Journal of Case Reports 2017;7(4):396-399

\title{
Deltoid Hypoplasia in a 14 year old boy with Duane's Syndrome
}

\author{
Rick Houben ${ }^{1}$, Andy Mckee $^{2}$, Frans-Jozef Vandeputte ${ }^{3}$ \\ ${ }^{1}$ Orthopaedic surgeon, Upper Limb Unit, AZ Turnhout, Belgium; ${ }^{2}$ Orthopaedic surgeon (FRCS), Upper Limb Unit, Peterborough \\ and Stamford Hospitals trust; ${ }^{3}$ University Hospitals Leuven, Department of Orthopaedics, B-3000 Leuven, Belgium.
}

\section{Corresponding Author: \\ Dr. Rick Houben \\ Email: rick.houben@telenet.be}

This is an Open Access article distributed under the terms of the Creative Commons Attribution License (creativecommons.org/ licenses/by/3.0).

Received Accepted

November 11, 2017

Published

\begin{abstract}
Background: Duane's retraction syndrome is a congenital ocular motility disorder characterized by limitation of abduction and/or adduction of the involved eye. Duane's syndrome is often associated with congenital musculo-skeletal (particularly upper limb) and neural malformations. Case Report: We describe the unusual association of a Type 1 unilateral Duane's with an atraumatic ipsilateral hypoplasia of the deltoid muscle in an otherwise active 14 year old boy. Conclusion: A child with upper limb musculo-skeletal abnormalities should undergo full orthopaedic, medical and ophthalmologic assessment.
\end{abstract}

Keywords: Deltoid Muscle, Duane Retraction Syndrome, Musculoskeletal Diseases, Ocular Motility Disorder, Upper Extremity.

\section{Introduction}

Deltoid atrophy is often seen after brachial plexus trauma, isolated axillary nerve lesions, as a result of neurological impairment such as mononeuritis multiplex, or myalgic amotrophy. It may be associated with certain systemic diseases like poliomyelitis [1]. There are also some case reports of deltoid muscle dysfunction following intramuscular injections [2]. Duane's retraction syndrome (DRS) is a congenital disorder with a limitation of abduction and/or adduction of the eye. In $70 \%$ of patients, DS is the only disorder the individual has. However, other conditions and syndromes have been associated with DS. These include malformation of the skeleton, ears, eyes, kidneys, and nervous system. DRS appears to be associated with an increasing number of musculoskeletal abnormalities affecting mainly the upper limb [3-6]. It can be co-inherited with radial ray anomalies and hearing loss as an autosomal dominant trait, referred to as 'Okihiro syndrome' or 'Duane's Radial Ray syndrome'[7,8]. Radial dysplasia can range from hypoplasia of the thenar eminence with or without thumb abduction and apposition weakness, hypoplasia or absence of the thumb, and hypoplasia or complete absence of the radius and ulna. Associations with absent or hypoplastic upper limb muscles have been described in the Holt-Oram syndrome (associated with cardiac malformations) [6,9]. It has been documented in Wildervanck syndrome (fusion of neck vertebrae and hearing loss), KlippelFeil (congenital fusion C2-C7) and in Poland's syndrome (pectoralis muscle hypoplasia). Type 1 Duane's syndrome is the most frequent form and can be associated with Klippel-Feil syndrome, thenar hypoplasia with or without absence of the thumb and first metacarpal, and deafness [3-5].

Numerous theories concerning the etiology and pathogenesis of DRS and its relation to the associated findings have been studied, but the exact mechanism is still being investigated. The most likely cause is a teratogenic stimulus during early gestation. Loci for Duane anomaly have been mapped to chromosomes $2 \mathrm{q}, 8 \mathrm{q}$ and 22 and lately mutations in SAL genes represent the first identified Duane Syndrome gene [7,10]. Although it may occasionally be seen as a familial feature, 
usually transmitted in autosomal dominant fashion, most patients with Duane's related anomalies are sporadic cases.

\section{Case Report}

A 14 year old fit and healthy right handed boy presented to our paediatric orthopaedic clinic, having noticed a difference between his right and left shoulder in the rugby club changing room. His right shoulder looked 'bony' compared to the left [Fig.1,2]. He had no history of pain, although he did get some discomfort in his right shoulder when he had to write for longer than 30 minutes at school. His mother had a normal uncomplicated delivery at 35 weeks. He followed a standard vaccination program. Only one uneventful injection was given into the right deltoid. At the age of seven months his mother took him to the ophthalmologist because she noticed his inability to abduct his right eye. At that time the diagnosis of Duane's retraction syndrome type 1 was made. No other abnormalities were noticed at that time. There was no history of
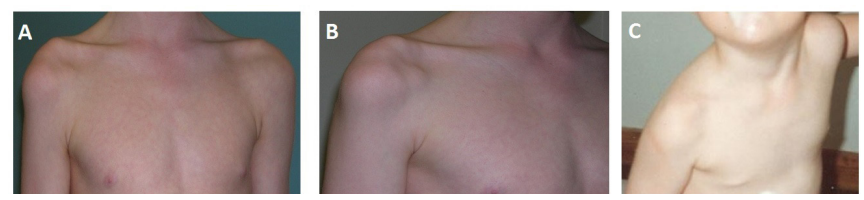

Fig.1(a): Frontal view. Deltoid hypoplasia in the right shoulder looking 'bony' compared to the left. (b): Anterolateral view. Deltoid hypoplasia in the right shoulder looking 'bony' compared to the left. (c): As a toddler one can already presume a hypoplasia of the right deltoid muscle.
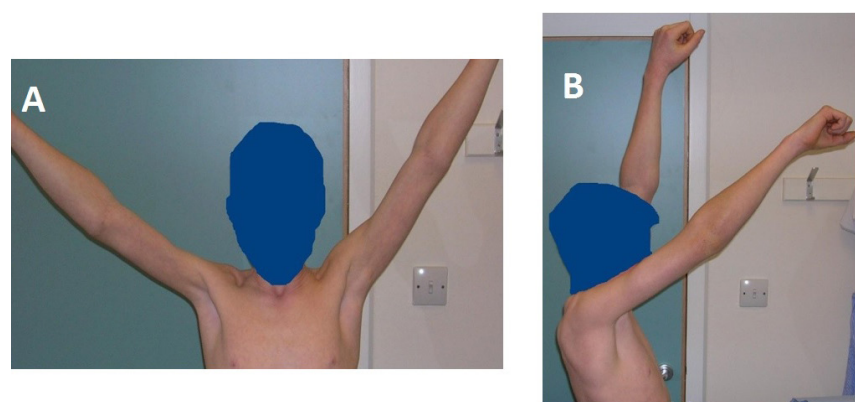

Fig.2(a): Frontal view. Decrease in right shoulder abduction compared to the left shoulder. (b): Lateral view. Decrease in frontal elevation of the right shoulder compared to the left. shoulder or upper limb trauma, and no history of humeral osteomyelitis during his childhood.

On pictures as a toddler, one can already appreciate a hypoplasia of the right deltoid muscle [Fig.1c]. There was no significant family history. Examination of his limbs was, with the exception of his right shoulder, completely normal. There was a slight decrease in shoulder abduction and forward elevation compared to the normal left shoulder $\left(120^{\circ}\right.$ versus $\left.150^{\circ}\right)$, but otherwise the range of motions (ROM) between the two shoulders were similar. The overall Constant score was 64 on the right as compared with 85 on the left. The left side lost 15 points on strength as well on pain and ROM [Table 1]. X-rays of both shoulders, cervical spine and forearms did not show any bony pathology, but the hooked contouring of his right shoulder is quite remarkable [Fig. 3a].

The subacromial space was identical to the left shoulder. A MRI was performed and this clearly demonstrated the hypoplasia of the deltoid muscle, with some fibre-like muscle remnants, and hyperplasia of the rotator cuff, particularly the supraspinatus [Fig.3b,c]. An EMG was done to rule out an agenesis of the deltoid muscle or an axillary nerve palsy. This investigation demonstrated a normal insertional activity without spontaneously activity during rest nor any large polyphasic units or other changes suggestive of re-innervation.
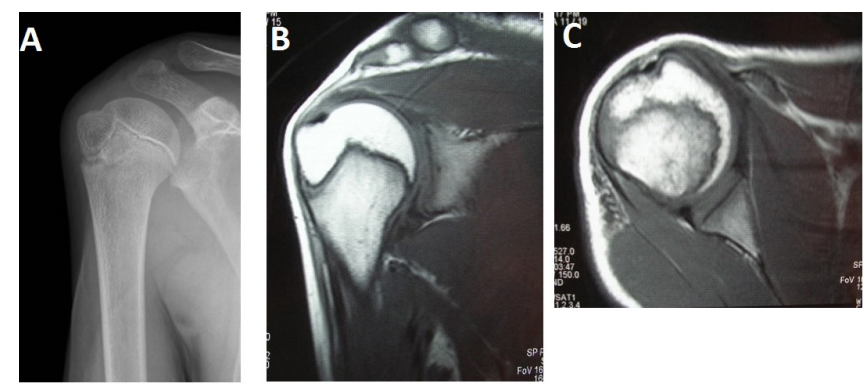

Fig.3(a): Frontal view X-ray right shoulder, remarkable hooked contouring. (b): MRI-scan right shoulder, frontal view. Few muscle fibers are present but have a non-physiological function. (c): MRI-scan right shoulder, horizontal view, remarkable hypertrophy of the rotator cuff. 


\section{Discussion}

In this case the deltoid hypoplasia is of a nontraumatic aetiology. Most likely the hypoplasia was already present at birth but not yet visible because of the physiological amount of subcutaneous fat in the infant. Duane's retraction syndrome has been associated with upper limb deformities in the hands [3-5,7], but, as far as we know, there are no reports of isolated unilateral ipsilateral deltoid hypoplasia in association with the syndrome. Although the term muscle fibrosis suggests that syndromes under this heading are primary disorders of muscle, evidence suggests that DRS may be a primary disorder of nerve innervation. Literature states that post-mortem studies did not identify large motor neurons at levels which the abducens nuclei normally occupy. It seems that some remaining muscle fibres are present but have a non-physiological function as seen on the EMG. One would need a biopsy of the remaining deltoid muscle fibres or an extensive DNA research to document the ongoing process. This patient is not significantly troubled by the lack of movement of his right shoulder. He is more concerned with the aesthetic appearance.

Although there are several procedures that could be considered to deal with his aesthetic concerns, it is the authors' opinion that the risks of any such procedure outweigh the possible benefits. His rotator cuff is markedly hypertrophied. This raises the possibility that he may develop a premature impingement like syndrome with overstuffing of the sub-acromial space that may require surgery at an unusually young age.

\section{Conclusion}

It seems to be fair that children presenting with Duane's retraction syndrome should be evaluated with X-rays of cervical spine and upper limbs for associated musculoskeletal abnormalities other than to the hand. Upper limb musculoskeletal abnormalities appear to be associated with an increasing number of syndromes. If such
Table 1: Constant shoulder score of right and left shoulder.

\begin{tabular}{|l|l|l|l|}
\hline & Right & Left & Maximal score \\
\hline PAIN & 7 & 15 & 15 \\
\hline ADL & & & \\
\hline Work & 2 & 4 & 4 \\
\hline Sport & 3 & 4 & 4 \\
\hline Sleep & 2 & 2 & 2 \\
\hline Position & 10 & 10 & 10 \\
\hline ROM & & & \\
\hline Flexion & 8 & 10 & 10 \\
\hline Abduction & 8 & 10 & 10 \\
\hline External rotation & 10 & 10 & 10 \\
\hline Internal rotation & 8 & 10 & 10 \\
\hline STRENGTH & 6 & 10 & 25 \\
\hline Total & 64 & 85 & 100 \\
\hline
\end{tabular}

abnormalities are found in the paediatric population, a full orthopaedic, medical and ophthalmologic assessment would seem to be essential.

Contributors: RH: manuscript writing, literature review, and patient management; AM: manuscript editing, literature review, and patient management; FJV: critical inputs into the manuscript, and patient management. RH will act as guarantor. All authors approved the final version of this manuscript.

Funding: None; Competing interests: None stated.

\section{References}

1. Kumar K, Kapahtia NK. The pattern of muscle involvement in poliomyelitis of the upper limb. Int Orthop. 1986;10:11-15.

2. Bodor M, Montalvo E. Vaccination-related shoulder dysfunction. Vaccine. 2007;25:585-587.

3. Kargi SH, Koç F, Kargi E, Aköz T, Firat E. Bilateral Duane retraction syndrome associated with an extraordinary hand anomaly. Strabismus. 2003;11:157162.

4. Okihiro MM, Tasaki T, Nakano KK, Bennett BK. Duane syndrome and congenital upper-limb anomalies. A familial occurrence. Arch Neurol. 1977;34:174-179.

5. Pernot C, Dupuis C, Gilgenkrantz S, Hueber JM. HoltOram syndrome and hand malformations associated with congenital heart disease. Arch Mal Coeur Vaiss. 1970;63:1428-1444.

6. Ferrell RL, Jones B, Lucas RV. Simultaneous occurrence of the Holt-Oram and the Duane syndromes. J Pediatr. 1966;69:630-634. 
7. Al-Baradie R, Yamada K, St Hilaire C, Chan WM, Andrews $\mathrm{C}$, McIntosh $\mathrm{N}$, et al. Duane radial ray syndrome (Okihiro syndrome) maps to 20q13 and results from mutations in SALL4, a new member of the SAL family. Am J Hum Genet. 2002;71:1195-1199.

8. Chun BB, Mazzoli RA, Raymond WR. Characteristics of Okihiro syndrome. J Pediatr Ophthalmol Strabismus. 2001;38:235-239.
9. Cascos AS. Holt-Oram syndrome. Acta Paediatr Scand. 1967;56:313-317.

10. Vincent C, Kalatzis V, Compain S, Levilliers J, Slim R, Graia $\mathrm{F}$, et al. A proposed new contiguous gene syndrome on $8 \mathrm{q}$ consists of Branchio-Oto-Renal (BOR) syndrome, Duane syndrome, a dominant form of hydrocephalus and trapeze aplasia; implications for the mapping of the BOR gene. Hum Mol Genet. 1994;3:1859-1866. 